\title{
Association of Low Serum Vitamin D with Varying Degrees of Myopia in Students of FJMU
}

${ }^{1}$ Sana Naveed, ${ }^{2}$ Ghazala Naveed, ${ }^{2}$ Shireen Khawar, ${ }^{2}$ Shazo Sana

${ }^{1}$ Department of Medicine, Lahore General Hospital, Ameer-ud-Din Medical College, Lahor

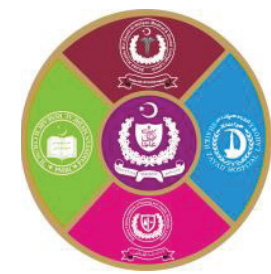

${ }^{2}$ Department of Physiology, Fatima Jinnah Medical University, Lahore

\begin{abstract}
Introduction: It has been found out that low vitamin $\mathrm{D}$, which is chemically 25 hydroxycholecalciferol $[25(\mathrm{OH}) \mathrm{D}]$, is related to myopia in children, adolescents and young adults. Myopia is usually corrected once diagnosed; still there is an increased risk of visual impairment or blindness owing to retinal detachment, lattice degeneration and angiogenesis in choroid. Moreover, myopia is also associated with high risk age related diseases of the eye such as cataract and glaucoma. Aims \& Objectives: This study was designed to find an association between serum $25(\mathrm{OH}) \mathrm{D}$ levels and myopia in the young adults. We also saw the influence of near work like studying, watching television, time spent on laptop, cell phone and household chores on myopia. Furthermore, we ascertained an association between serum 25(OH) D and time spent outdoors in the sun. Place and duration of study: It was conducted in Fatima Jinnah Medical University, Lahore. The study duration was May 2017 to September 2018. Material \& Methods: This was a crosssectional study. We selected 70 myopic students from first and second year classes of MBBS. Demographic data was collected through a questionnaire. The extent of myopia was correlated with the quantity of serum $25(\mathrm{OH}) \mathrm{D}$ which was estimated in blood by ELISA technique. Multiple linear regression analyses were performed to examine the link between serum $25(\mathrm{OH}) \mathrm{D}$ and myopia. Results: The association between myopia and serum $25(\mathrm{OH}) \mathrm{D}$ was found to be significant with a $\mathrm{p}$ value of 0.000 and 0.002 in mild and moderate myopia respectively. We could also find significant association of serum vitamin D levels and daily sun exposure time with a $\mathrm{p}$ value of 0.004 . Conclusion: Low serum $25(\mathrm{OH}) \mathrm{D}$ was associated with high prevalence of myopia in the students of FJMU. This alliance was particularly remarkable in the group of mild myopics.
\end{abstract}

Key words: Myopia; vitamin D; Sun exposure

\section{INTRODUCTION}

$\mathrm{T}$ he dilemma of myopia has increased in East Asia predominantly in China and Singapore. In children of 12 years, the prevalence of myopia is $62 \%$ in Singapore while in China it is $49.7 \%$. It is only $20 \%$ in United States. ${ }^{1}$

Myopia or nearsightedness is a refractive error in which a distant object makes its image in front of retina, thus producing a blurred image. Myopia is of two types: axial and refractive. In the axial type, there is an increase in axial length due to an oblong eyeball. In refractive type, the refractive power of lens or cornea is more than standard. ${ }^{2}$

The main cause of myopia is a developmental disparity among the optical components of the eye, especially, axial length and corneal radius of curvature ratio. However, axial length is the more imperative issue of the two. ${ }^{3}$ Genetic factors are deep-rooted among the causes of myopia ${ }^{4}$. Environmental factors such as lingering near work, years of education, time spent out-of-doors and watching TV; all count in the incidence and severity of myopia. 2,5,6,7,8 However, education has been recognized as the most crucial environmental risk factor. The risk of myopia has been found to be four times higher in university level students as compared to those who finished studies at primary stage.., 8

Myopia is by and large corrected once diagnosed; still there is an increased risk of visual impairment or blindness owing to retinal detachment, lattice degeneration and angiogenesis in choroid. Moreover, myopia is also associated with high risk age linked diseases of the eye such as cataract and glaucoma. ${ }^{9}$ Recently, it has been found out that low serum vitamin $\mathrm{D}$, which is chemically 25 
hydroxycholecalciferol $(25(\mathrm{OH}) \mathrm{D})$, is related to myopia in children, adolescents and young adults. ${ }^{10-14}$

This study was designed to find an association between serum $25(\mathrm{OH}) \mathrm{D}$ levels and myopia in the young adults. We also saw the influence of near work like studying, time spent on laptop, cell phone and household chores on myopia. Furthermore, we ascertained an association between serum vitamin D levels and daily sun exposure time.

\section{MATERIAL AND METHODS}

\section{Study Population:}

This was a cross-sectional study. We selected 70 myopic students from first and second year classes of MBBS. The students who had mild, moderate and severe myopia were included in the study. Demographic data was composed through a questionnaire. The experiments were undertaken with the understanding and written consent of the students. Agreement of our study was obtained from the research ethical committee, FJMU.

\section{Sampling Technique:}

Convenient sampling

\section{Questionnaire:}

Each student filled a questionnaire concerning, daily close work like studying, time spent on laptop, mobiles and household chores. It also included time spent outdoors in the sun. The refractive error of each participant was also noted. The questions were asked for the entire week and answers were multiple choice: (Never, 1/2-1, 1-2, 2-3, 3-4 hours)

\section{Age and Gender:}

All participants were females with age in the range of 19-21 years.

\section{Inclusion/Exclusion Criteria:}

A student with any systemic disease was excluded.

Degrees of Myopia

Spherical equivalent (SE) refractive power was calculated as sphere $+1 / 2$ cylinder. Myopia was defined by SE of $-0.50 \mathrm{D}$ or more. Myopia was additionally classified as mild $<-3.00 \mathrm{D}$, moderate $3.00 \mathrm{D}$ to $-6.00 \mathrm{D}$ and severe $>-6.00 \mathrm{D} .^{10,11}$ Refractive error was defined based on the eye with bigger error.

\section{Assessment of Serum 25(OH) D}

Non-fasting blood samples were taken from antecubital vein and stored at $-80^{\circ} \mathrm{C}$ until analyses. The samples were collected by the lab staff of Chemical Pathology FJMU. Serum 25(OH) D was measured using ELISA in nanograms per milliliter $(\mathrm{ng} / \mathrm{ml})$. The kit was $25(\mathrm{OH}) \mathrm{D}$ Human, made in Germany.

\section{Statistical analysis:}

The data was entered and analyzed using SPSS version 21.0. The categorical variables were described using frequencies and percentages. The continuous variables were described using mean \pm SD (Table-1). Multiple Linear Regression analyses were used to scrutinize the association of serum $25(\mathrm{OH})$ D with varying extent of severity of myopia, to calculate approximately the measure of association of near work with myopia and to evaluate linkage of serum $25(\mathrm{OH}) \mathrm{D}$ levels and average daily sun exposure time. A p-value $<0.05$ was considered significant.

\section{RESULTS}

Among the study participants, 39 (56\%) were mildly myopic, $27(38 \%)$ were moderate and $4(6 \%)$ had severe myopia as given in Table-1. The association between myopia and serum vitamin D levels was significant with a p value of 0.000 and 0.002 for mild and moderate myopia respectively as shown in Fig-1 \& 2. However, the association between severe myopia and serum $25(\mathrm{OH}) \mathrm{D}$ was not significant as the number of myopes in this group were fewer (Fig-3); nevertheless the students in this group had very low serum vitamin D levels. There was a positive relationship between serum $25(\mathrm{OH}) \mathrm{D}$ and refractive error $\left(\mathrm{R}^{2}=+0.388, \mathrm{p}=0.000\right)$ in mild myopia. (Fig-1) Similarly, in moderate myopia, there was significant positive relation $\left(\mathrm{R}^{2}=+0.336\right.$ $\mathrm{p}=0.002)$ between serum $25(\mathrm{OH}) \mathrm{D}$ and refractive error (Fig-2). The more myopic subjects had worse serum levels of vitamin D while less myopic subjects had elevated serum levels of vitamin D showing a direct relation.

We could also find significant association between serum $25(\mathrm{OH}) \mathrm{D}$ and daily sun exposure time $\left(\mathrm{R}^{2}=\right.$ $+0.115, \mathrm{p}=0.004)$ as shown in Fig-4. Greater the daily exposure to sun higher was the serum vitamin D intensity showing direct relation. There is no association of myopia with other potential confounding factors such as time spent outdoors in the sun and close work such as studying, watching television, use of laptop and cell phone.

\begin{tabular}{|l|c|c|c|c|c|}
\hline & $\mathbf{N}$ & Min. & Max. & Mean & $\begin{array}{c}\text { Std. } \\
\text { Deviation }\end{array}$ \\
\hline Mild myopia & 39 & 1.50 & 2.75 & 1.7154 & 1.15816 \\
\hline Moderate myopia & 27 & 3 & 5 & 3.7907 & .71267 \\
\hline Severe myopia & 4 & 7 & 6 & 6.3250 & .45552 \\
\hline
\end{tabular}

Table-1: Distribution of varying Degrees of Myopia 


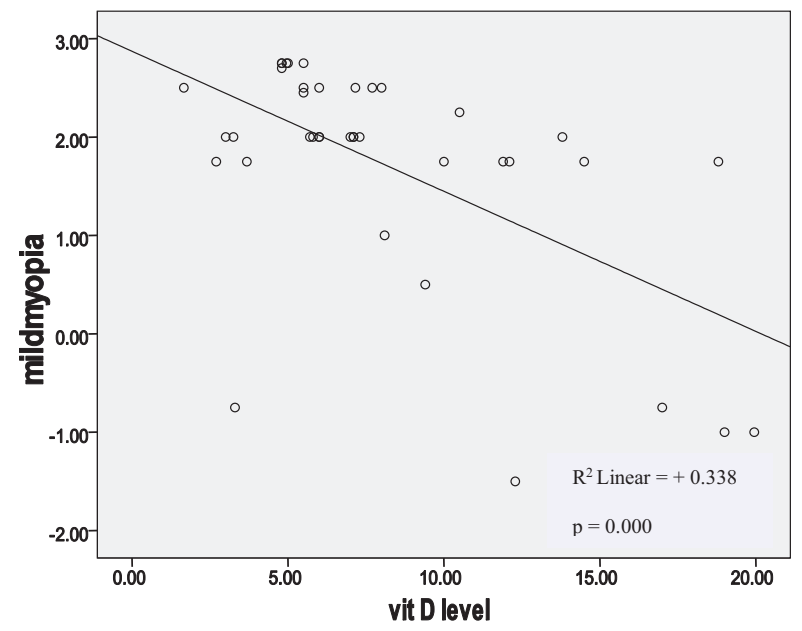

Fig-1: Scatter plot showing direct relation between mild myopia (SE) and serum 25(OH) D levels (ng/ml)

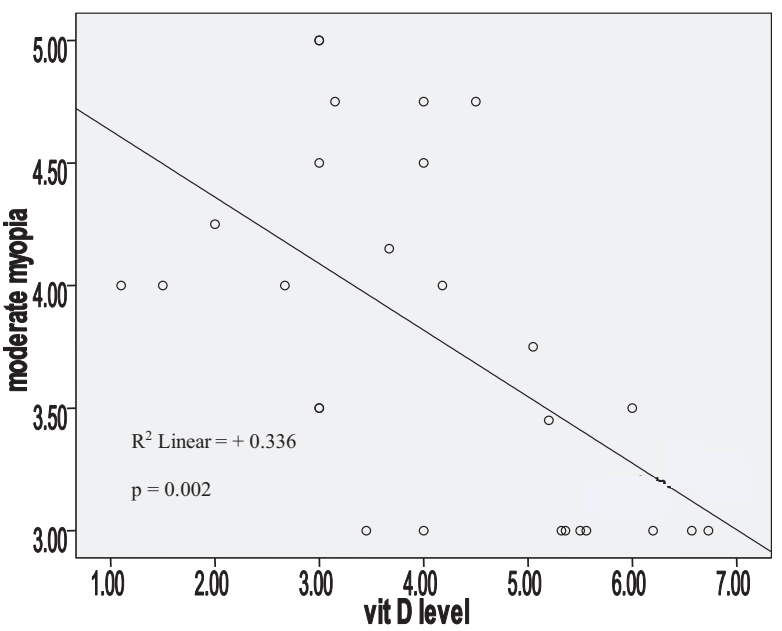

Fig-2: Scatter plot showing direct relation between moderate myopia (SE) and serum $25(\mathrm{OH})$ D levels (ng/ml)



Fig-3: Scatter plot showing slight positive relation between severe myopia (SE) and serum $25(\mathrm{OH}) \mathrm{D}$ levels $(\mathrm{ng} / \mathrm{ml})$

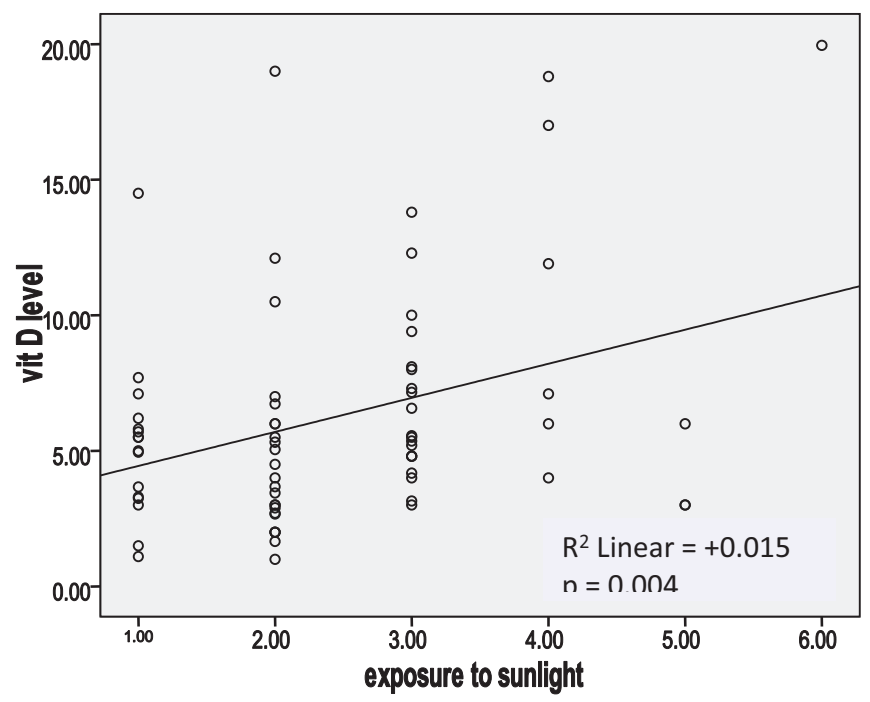

Fig-4: Scatter plot showing a positive relation between exposures to sunlight (time in hours) and serum 25(OH) D levels (ng/ml)

\section{DISCUSSION}

To the best of our knowledge, our novel study in Pakistan showed a significant relationship between serum vitamin $\mathrm{D}$ and mild to moderate myopia. There was no association of myopia with other prospective confounding factors such as time spent outdoors in the sun and of close work such as studying, watching television, use of laptop and cell phone. A similar relation existed in a survey carried out in Korea in $2015^{10}$; there are a small number of other studies consistent with the results of our study. The researchers have targeted all growth periods, reaching to the conclusion that associations exist invariably in young children, teenage, adolescents and young adults. ${ }^{11-14}$ In view of these results, serum $25(\mathrm{OH}) \mathrm{D}$ is probably a self-regulating interpreter for the refractive error.

Physiologically the 25(OH) D serum level represents the intake and principal endogenous production of vitamin $\mathrm{D}$ by the liver and is measured to determine the clinical status of vitamin D. ${ }^{15-17}$ The active form $1,25(\mathrm{OH})_{2} \mathrm{D}_{3}$ is produced in the kidney by the action of an enzyme 1 alpha- hydroxylase, in the presence of parathormone. Once produced in the kidney, it circulates in the body and exerts ample effects. The active form regulates metabolism of phosphate and calcium by acting on intestines, kidney and bone. ${ }^{15}$ Certain cytokines also liberate $1,25(\mathrm{OH})_{2} \mathrm{D}$ and is said to be involved in paracrine regulation of cell differentiation, function and growth. ${ }^{18}$ Some studies support polymorphism of vitamin $\mathrm{D}$ receptor gene in myopics. ${ }^{19,20}$ However, the mechanism for the 
progression of myopia by the deficiency of $25(\mathrm{OH})$ $\mathrm{D}$ is not known. ${ }^{12}$

In contrast other research has found low serum vitamin $\mathrm{D}$ to be involved directly in the development of myopia. There may be impaired contraction and relaxation of ciliary muscle as vitamin D is coupled with alteration of intracellular calcium level. Low calcium derived from low vitamin D could be accountable for malformation of skull including the orbit. This subsequently leads to myopia of prematurity which cannot be corrected by means of calcium supplements in exceptionally low birth weight infants. ${ }^{11}$

Some researchers suggest that $25(\mathrm{OH}) \mathrm{D}$ may be involved in retinoscleral signaling pathways. Retinoic acid is a metabolite of vitamin A required for growth and development of eye ball. However, retinoic acid is capable of operating when its receptor and $25(\mathrm{OH}) \mathrm{D}$ receptor heterodimerize with retinoid X receptors. ${ }^{10,11}$ High myopia is supposed to be associated with abnormal changes, such as thinning of sclera, lesser collagen and scleral tissue. Moreover, high myopes have significantly increased intra ocular pressure. Multiple studies have revealed significant consequences of raised intra ocular pressure on the progression of myopia. ${ }^{10,21-24}$

Exposure to sunlight is an encouraging factor in preventing myopia and it has been shown by multiple studies. ${ }^{15-18,25}$ In our study we found a significant relation between serum vitamin D level and daily exposure to sunlight, where vitamin D level is a dependent variable. Most students of FJMU live in hostels so there is an unavoidable walk of at least 20 minutes twice a day. A study carried by Need et $\mathrm{al}^{26}$ has shown that serum level of $25(\mathrm{OH}) \mathrm{D}$ is positively associated to hours of sunlight exposure. Moreover, lack of sun exposure is generally acknowledged as the crucial cause of low vitamin D status. ${ }^{27}$ However, some suffer from low vitamin D in spite of adequate sun exposure especially in South Asia and South East Asia. ${ }^{28,29}$ Multiple reasons have been endorsed to this low vitamin $\mathrm{D}$, like wearing of sunscreens, covering most body parts with clothes, increased skin pigmentation and aging. ${ }^{28,30}$

The mechanisms which explain the role of time spent outdoors in the development of myopia are poorly understood. There is a hypothesis that retina releases more dopamine in sunlight which depress the elongation of axial length of eyeball thereby enhancing depth of focus with the minimum use of power of accommodation for distant vision. ${ }^{31}$ However, Mutti et al suggested that decrease in axial length of eye ball may also be due to skin formation of vitamin $\mathrm{D}$ in sunlight.

\section{Limitations of the Study:}

The present study has some limitations. It is a crosssectional, analytical study designed to evaluate the association between $25(\mathrm{OH}) \mathrm{D}$ and myopia targeting limited population with the age range of 19-21 years. In this age group the refractive error has not become stable. In order to reach a definite causal relation of myopic progression and $25(\mathrm{OH}) \mathrm{D}$, cohort study design would be more worthwhile.

\section{CONCLUSION}

The association between myopia and serum vitamin D levels was significant for mild and moderate myopia. The high myopic subjects had lower levels of vitamin $\mathrm{D}$ while less myopic subjects had higher levels of vitamin D. We could also locate significant association between serum vitamin D levels and daily sun exposure time. Greater the daily exposure to sun higher is the serum vitamin D level.

It is essential to create awareness of the effects of near sightedness among the public. Efforts are required to enhance the serum level of $25(\mathrm{OH}) \mathrm{D}$ by food supplementation and engaging the children to spend more time in the sun to avert myopia.

\section{Acknowledgements:}

The authors would like to acknowledge the efforts of Professor Dr. Farrukh and his Medical Offier, Dr. Atta-ur-Rehman of Pathology department of FJMU, who facilitated the students for the vitamin $\mathrm{D}$ test in the laboratory of Chemical Pathology.

\section{REFERENCES}

1. Jonas JB, Xu L, Wei WB, Wang YX, Jiang WJ, Bi HS, Panda-Jonas S. Myopia in China: a population-based cross-sectional, histological, and experimental study. Lancet. 2016 Oct; 388

2. Verma A, Verma A. A novel review of the evidence linking myopia and high intelligence. $\mathrm{J}$ Ophthalmol. Epub 2015 Jan 11.

3. González Blanco F, Sanz Ferńandez JC, Muńoz Sanz MA. Axial length, corneal radius, and age of myopia onset. Optom Vis Sci. 2008 Feb; 85(2):89-96.

4. Genetic susceptibility and mechanisms for refractive error. Stambolian D Clin Genet. 2013 Aug; 84(2):102-8.

5. Verhoeven VJ, Buitendijk GH; Consortium for Refractive Error and Myopia(CREAM)., Rivadeneira F, Uitterlinden AG, Vingerling JR, Hofman A, Klaver CC.Education influences the role of genetics in myopia. Eur $\mathrm{J}$ Epidemiol. 2013Dec; 28(12):973-80. 
6. SawS-M, ChuaW-H, HongC-Y, et al. Nearwork in early-onset myopia. Invest Ophthalmol Vis Sci. 2002; 43:332-33

7. MuttiDO, MitchellGL, MoeschbergerML, JonesLA, ZadnikK. Parental myopia, near work, school achievement, and children's refractive error. Invest Ophthalmol Vis Sci. 2002;4:3633-40

8. Teasdale TW, FuchsJ, GoldshmidtE. Degree of myopia in relation to intelligence and educational level. Lancet. 1988; 2: 1351-1354.

9. How blinding is pathological myopia? Saw SM Br J Ophthalmol. 2006 May;90(5):525-6

10. Kwon JW, Choi JA, La TY. Serum 25hydroxyvitamin D level is associated with myopia in the Korea national health and nutrition examination survey. Medicine (Baltimore). 2016 Nov; 95(46):e5012.

11. Choi JA, Han K, Park YM, La TY. Low serum 25-hydroxyvitamin D is associated with myopia in Korean adolescents. Invest Ophthalmol Vis Sci. 2014 Apr3;55(4): 2041-7

12. Tideman JW, Polling JR, Voortman T, Jaddoe VW, Uitterlinden AG, Hofman A, Vingerling JR, Franco OH, Klaver CC. Low serum vitamin $\mathrm{D}$ is associated with axial length and risk of myopia in young children. Eur J Epidemiol. 2016 May; 31(5): 491-9.

13. Mutti DO Marks AR. Blood levels of vitamin D in teens and young adults with myopia. Optom Vis Sci . 2011; 88: 377-382.

14. Yazar S, Hewitt AW, Black LJ, et al. Myopia is associated with lower vitamin D status in young adults. Invest Ophthalmol Vis Sci. 2014; 55(7):4552-9.

15. Holick MF. Vitamin D deficiency. N Engl J Med. 2007 Jul 19; 357(3):266-81.

16. Hollis BW. Circulating 25-hydroxyvitamin D levels indicative of vitamin D sufficiency: implications for establishing a new effective dietary intake recommendation for vitamin D. J Nutr. 2005 Feb; 135(2):317-22.

17. Muller DN Kleinewietfeld M Kvakan $H$. Vitamin D review. $J$ Renin Angiotensin Aldosterone Syst. 2011; 12: 125-128

18. Zehnder D, Bland R, Chana RS, Wheeler DC, Howie AJ, Williams MC, Stewart PM, Hewison M. Synthesis of 1,25-dihydroxy vitamin $\mathrm{D}(3)$ by human endothelial cells is regulated by inflammatory cytokines: a novel autocrine determinant of vascular cell adhesion. J Am Soc Nephrol. 2002 Mar; 13(3):621-9.

19. Annamaneni S, Bindu CH, Reddy KP, et al. Association of vitamin $\mathrm{D}$ receptor gene start codon (Fok1) polymorphism with high myopia. Oman J Ophthalmol 2011; 4:57-62.
20. Mutti DO, Cooper ME, Dragan E, et al. Vitamin $\mathrm{D}$ receptor (VDR) and group-specific component (GC, vitamin D-binding protein) polymorphisms in myopia. Invest Ophthalmol Vis Sci 2011; 52:3818-3824.

21. Jeong da W, Kook MS, Lee KS, et al. Circadian pattern of intraocular pressure fluctuations in young myopic eyes with open-angle glaucoma. Invest Ophthalmol Vis Sci 2014; 55:2148-2156.

22. Yang $\mathrm{Y}$, Li $\mathrm{Z}$, Wang $\mathrm{N}$, et al. Intraocular pressure fluctuation in patients with primary open-angle glaucoma combined with high myopia. J Glaucoma 2014; 23:19-22.

23. Yan L, Huibin L, Xuemin L. Accommodationinduced intraocular pressure changes in progressing myopes and emmetropes. Eye(Lond) 2014;28:1334-1340

24. Choi JA, Han K, Park YM, et al. Age-related association of refractive error with intraocular pressure in the Korea National Health and Nutrition Examination Survey. PLoS One 2014; 9:111879.

25. Rose KA, Morgan IG, Ip J, Kifley A, Huynh S, Smith W, Mitchell P. Outdoor activity reduces the prevalence of myopia in children. Ophthalmology. 2008 Aug; 115(8):1279-85.

26. Need AG, Morris HA, Horowitz M, Nordin C. Effects of skin thickness, age, body fat, and sunlight on serum 25-hydroxyvitamin D. Am J Clin Nutr 1993;58:882

27. Binkley N, Novotny R, Krueger D, et al. Low vitamin $\mathrm{D}$ status despite abundant sun exposure. J Clin Endocrinol Metab 2007; 92:2130.

28. Hataikarn Nimitphong, Michael F. Holick. Vitamin D status and sun exposure in southeast Asia. Dermatoendocrinol.2013 Jan 1;5(1):34-37

29. Riaz H, Finlayson AE, Bashir S, Hussain S, Mahmood S, Malik F, Godman B. Prevalence of Vitamin D deficiency in Pakistan and implications for the future. Expert Rev Clin Pharmacol. 2016; 9(2):329-38.

30. Farrar MD, Kift R, Felton SJ, et al. Recommended summer sunlight exposure amounts fail to produce sufficient vitamin D status in UK adults of South Asian origin. Am J Clin Nutr 2011; 94: 1219-1224.

31. Feldkaemper M, Schaeffel F. An updated view on the role of dopamine in myopia. Exp Eye Res. 2013 Sep; 1140:106-19 
The Authors:

Dr. Sana Naveed,

House officer,

Department of Medicine,

Lahore General Hospital.

Ameer-ud-Din Medical College, Lahore.

Dr. Ghazala Naveed,

Associate Professor,

Department of Physiology,

Fatima Jinnah Medical University, Lahore.

Prof. Shireen Khawar,

Department of Physiology,

Fatima Jinnah Medical University, Lahore.
Dr. Shazo Sana

Demonstrator,

Department of Physiology,

Fatima Jinnah Medical University, Lahore.

\section{Corresponding Author:}

Dr. Ghazala Naveed,

Associate Professor,

Department of Physiology,

Fatima Jinnah Medical University, Lahore.

E-mail: ghazalanaveed@outlook.com 